fat to inflammation: Old questions and new insights. Febs Lett. 2005; 579: 295-301.

Disclosure of Interest: None declared

DOI: 10.1136/annrheumdis-2017-eular.6722

\section{AB0242 EVALUATION OF VARIANTS IN MIR-146A, MIR-196A-2 AND MIR-499 AND THEIR ASSOCIATION WITH SUSCEPTIBILITY FOR RHEUMATOID ARTHRITIS AND ITS EXTRA-ARTICULAR MANIFESTATIONS}

J.C. De La Cruz-Castillejos, R.E. Barbosa-Cobos, L.T. Becerril-Mendoza, G.E. Lugo-Zamudio, J. Ramírez-Bello, M. Matias-Carmona, I. Alemán-Ávila Hospital Juárez de México, Ciudad de México, Mexico

Background: The miRNAs, small non-coding RNA, regulate the genetic expression to posttranscriptional level, inhibiting the translation. The role of miRNAs in the evolution of RA is not clear.

Objectives: To evaluate the variants rs 2910164G/C in miR-146a, rs11614913C/T in miR-196a-2 and rs3746444A/G in miR-499 and their association with susceptibility and severiry to Rheumatoid arthritis (RA) and its extra-articular manifestations (EAM)

Methods: 133 cases with RA were included (ACR/EULAR criteria 2010) and 430 healthy controls. There were evaluated EAM (rheumatoid nodules [RN], Raynaud phenomenon [RP], cutaneous vasculitis (CV), episcleritis, scleritis, peripheral ulcerative keratitis [PUK], multiple mononeuritis [MM] and multiple polyneuritis [MP]) and levels of ESR, CRP, RF and CCP. It was performed genotyping of singe nucleotide polymorphisms (SNPs) rs2910164G/C in miR-146a, rs11614913C/T of miR-196a-2 and rs3746444A/G of miR-499. The descriptive and inferential statistical analysis was performed with the software SPSS and Finetti.

Results: Patients with RA, women 126 (94.7\%); age Me 48.9 (IQR 40-58); patients with EAM 23 (17.2\%; women 22 [95.6\%]; RN 14 [60.8\%], RP 4 [17.3\%], CV 1 [4.3\%], episcleritis 1 [4.3\%], PUK 1 [4.3\%], MM 1 [4.3\%], MP 1 [4.3\%]); ESR Me 37 (IQR 22-45), CRP Me 0.11 (IQR 0.03-0.27); positive RF 125 patients (93.9\%, high positive 106 [79.7\%], low positive 19 [14.3\%]; EAM with high positive RF, $100 \%$ ), positive CCP 70 (52.6\%, high positive $48.9 \%$, low positive $3.8 \%$; EAM high positive $94.1 \%$, negative $5.9 \%$ ). The alleles and genotypic frequencies did not show statistically significant difference between cases and the healthy controls $(p>0.05)$. It was identified statistical difference between the patients with and without EAM in CPR $(p=0.032)$. The genotypic and allelic frequencies and association analysis of miRNAs in patients with and without EAM are shown in table 1

Table 1. Anaysis of the genotypic and aleles frequencies of the SNPs rs20101640.C from miR-1460, rs11614913CrT from mR-1960-2 and rs3746444,Na from miR-49? in patients with $R A$ with and whout EAM

\begin{tabular}{|c|c|c|c|c|c|c|c|}
\hline \multirow{4}{*}{ 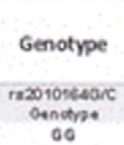 } & \multirow{2}{*}{\multicolumn{2}{|c|}{ Patients without EAM }} & \multirow{2}{*}{\multicolumn{2}{|c|}{ Patients with EAM }} & \multirow{3}{*}{$O R$} & \multirow{3}{*}{$\begin{array}{c}\text { a } \\
95 \%\end{array}$} & \multirow{3}{*}{$p$} \\
\hline & & & & & & & \\
\hline & $n$ & $\checkmark$ & $n$ & $s$ & & & \\
\hline & $\$ 4$ & (52) & , & (39.1) & - & - & - \\
\hline$\propto$ & 47 & $(42 \pi)$ & 11 & $(47.8)$ & 140 & $\begin{array}{l}0.54 \\
3.68\end{array}$ & 049 \\
\hline$c$ & ? & (2:2) & 3 & (23.6) & 200 & 0.45 & 0.35 \\
\hline \multicolumn{8}{|l|}{ Allele } \\
\hline 6 & 15s & (90.4) & 29 & 162.64 & - & - & - \\
\hline c & 65 & $(296)$ & 27 & (37.6) & 2.4 & $\begin{array}{l}0 . n \\
2 \pi\end{array}$ & 0.32 \\
\hline \multicolumn{8}{|l|}{ 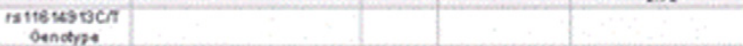 } \\
\hline 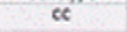 & 42 & $02:$ & 2 & $(2 n)$ & - & - & - \\
\hline $\mathrm{CT}$ & 55 & (5eo) & 24 & (so.s) & 5. .4 & $\begin{array}{l}1.15 \\
24.31\end{array}$ & 0.02 \\
\hline$\pi$ & 23 & (12.5) & , & 00.4) & $11 \mathrm{n}$ & $\begin{array}{l}2.09 . \\
61.29\end{array}$ & 0.001 \\
\hline \multicolumn{8}{|l|}{ Altele } \\
\hline C & 139 & (632) & 18 & 031) & - & - & - \\
\hline$T$ & 01 & (36) & 23 & (sa.s) & 2.6 & $\begin{array}{l}1.30 \\
5.22\end{array}$ & 0.002 \\
\hline \multicolumn{8}{|l|}{ 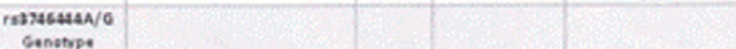 } \\
\hline MA & 200 & 929 & 21 & (2) $x$ & - & - & - \\
\hline No & , & (2.2) & 2 & $(t, n)$ & 2.06 & 0.21 . & 0.94 \\
\hline 00 & 2 & (0.5) & 6 & (0.9) & 2.56 & $\begin{array}{l}0.06 \text {. } \\
39.6\end{array}$ & 0.55 \\
\hline \multicolumn{8}{|l|}{ Nile? } \\
\hline A & $m 9$ & (25. ब) & 44 & (\$5.6) & - & - & - \\
\hline 0 & 12 & $(5.6)$ & 2 & (4.4) & $0 . x$ & 0.22 & 103 \\
\hline
\end{tabular}

Conclusions: None of the evaluated variants in miRNAs are associated with susceptibility for RA, however, the SNP re11614913C/T licated in miR-196a-2 is associated with EAM.

References:

[1] Churov AV, Oleinik EK, Knip M. MicroRNAs in rheumatoid arthritis: altered expression and diagnostic potential. Autoimmun Rev 2015;14:1029-37.
[2] Singh RP, Massachi I, Manickavel S, Singh S, Rao NP, Hasan S et al. The role of miRNA in inflammation and autoimmunity. Autoimmun Rev 2013;12:1160-5.

[3] Nakasa T, Nagata Y, Yamasaki K, Ochi M. A mini-review: microRNA in arthritis. Physiol Genomics 2011;1:566-70.

[4] Chung IM, Ketharmathan S, Thiruvengadam M, Rajajumar G. Rheumatoid Arthritis: The Stride from Research to Clinical Practice. Int J Mol Sci 2016;17. piiE900.

[5] LI K, Tie H, Hu N, Chen H, Yin X, Peng C et al. Association of two polymorphisms rs2910164 in miRNA-146a and rs3746444 in miRNA-499 with rheumatoid arthritis: a meta-analysis. Hum Immunol 2014;75:602-8.

[6] Hashemi M, Eskandari-Nasab E, Zakeri Z, Atabaki M, Bahari G, Jahantigh. Association of pre-miRNA-146a rs2910164 and pre-miRNA-499 rs3746444 polymorphisms and susceptibility to rheumatoid arthritis. Mol Med Rep 2013;7:287-9

[7] Lu L, Tu Y, Liu L, Qi J, He L. MicroRNA-499 rs3746444 polymorphism and autoimmune diseases risk: a meta-analysis. Mol Diagn Ther 2014;18:237-4.

Disclosure of Interest: None declared

DOI: 10.1136/annrheumdis-2017-eular.6500

\section{AB0243 SERUM LEVELS OF ANGIOGENIC AND PROINFLAMMATORY CYTOKINES TO DISCRIMINATE BETWEEN 6 SETS OF REMISSION CRITERIA IN RA}

J. Ramírez García, A. Cuervo, R. Celis, V. Ruiz-Esquide, M.V. Hernández, R. Sanmartí, J.D. Cañete. Rheumatology, Hospital Clínic, Barcelona, Spain

Background: The ideal definition of remission in RA remains to be agreed. Angiogenic factors and proinflammatory cytokines are key in RA pathogenesis. Objectives: The aim of this study was to analyse serum levels differences of angiogenic and inflammatory biomarkers between SDAI, CDAI, ACR, DAS28 and sonographic remission in patients with (RA).

Methods: We selected patients with RA in clinical remission (DAS28-ESR $<2.6$ for $>6$ months). PDUS of knees and hands was performed. Serum levels of biomarkers of inflammation/angiogenesis were determined by Quantibody ${ }^{\circledR}$ Human Array. Patients were classified according to 6 sets of remission criteria: SDAI (<3.3), CDAI (<2.8), ACR, DAS28-ESR (<2.6), Doppler (score Doppler=0) and UdAS (ultrasound defined active synovitis:no joints with $\mathrm{SH} \geq 2+\mathrm{PD}$ )

Results: 60 patients with RA were collected. 76\% female, aged (mean) 53 years; disease duration 110 months. 47 (76\%) csDMARDs, and 27 (45\%) biological therapies. At baseline, $67 \%$ of patients had PD signal and $48 \%$ fulfilled criteria for previously defined UdAS. Although patients in sonographic remission had lower levels of inflammatory biomarkers such as IL-6, IL-17 or IL-23, no significant differences were found between the 6 sets of remission criteria. Angiogenic biomarkers such as CXCL6 (0.039), ENA78 (0.007), SDF1 (0.047) and VEGF-R1 (0.025) were significantly lower in patients fulfilling CDAI remission. Patients with no PD signal (0.009) and no UdAS (0.006) had significantly lower levels of bFGF. Conclusions: RA patients in CDAl remission had significantly-lower levels of angiogenic cytokines. However, no differences in serum levels of proinflammatory cytokines were found between the 6 sets of remission criteria.

Disclosure of Interest: None declared

DOI: 10.1136/annrheumdis-2017-eular.3504

\section{AB0244 MICROWAVE RADIOMETRY-DERIVED THERMAL CHANGES OF SMALL JOINTS AS POTENTIAL ADDITIONAL BIOMARKER IN RHEUMATOID ARTHRITIS: A PROSPECTIVE STUDY}

K. Laskari ${ }^{1}$, G. Pentazos ${ }^{1}$, K. Prekas ${ }^{2}$, I. Raftakis ${ }^{3}$, E. Siores ${ }^{4}$, P.P. Sfikakis ${ }^{1}$ ${ }^{1}$ Rheumatology Unit, 1 st Dept. of Propaedeutic Internal Medicine and Joint Rheumatology Program, National \& Kapodistrian University of Athens Medical School; ${ }^{2}$ Technological Education Institute; ${ }^{3}$ Department of Rheumatology, Asklepion General Hospital, Athens, Greece; ${ }^{4}$ Institute of Materials Research and Innovation, University of Bolton, Bolton, United Kingdom

Background: Microwave Radiometry (MR) is a rapid, non-invasive method that detects in-depth tissue temperatures. Using joint ultrasound as reference method, in a proof-of-concept study, we have found that an increased temperature at the knee joint detected by MR in the absence of relevant clinical signs reflects the presence of subclinical synovial inflammation in rheumatoid arthritis (RA) (1). Objectives: To test the hypothesis that temperature of small joints assessed by MR correlates to global disease activity levels in RA, a disease in which small joints are primarily affected.

Methods: Ten patients with active, untreated RA underwent clinical and laboratory assessments, joint ultrasound and MR of hand and foot small joints (RTM 01 RES microwave computer based system, Bolton, UK) at baseline, as well as 15 , 30 and 90 days after treatment onset. Twenty aged-matched healthy individuals served as controls.

Results: Using 1248 separate MR-derived recordings from RA patients we created several thermo-scores involving different small joint combinations and compared them with clinical and ultrasound data. The best performing thermoscore involved the sum of temperatures of 16 small joints (2nd-5th metacarpal and proximal inter-phalangeal joints, bilaterally). This thermo-score correlated positively to DAS28 disease activity score $(p=0.001)$, tender joint count $(p=0.002)$, swollen joint count $(p=0.001)$, patient's visual analogue scale $(p<0.001)$, CRP 